\title{
Research on the Mode of Computer-Aided Translation Teaching
}

\author{
Zhang huiqin ${ }^{\mathrm{a}}$, Guo pingiian ${ }^{\mathrm{b}}$ \\ ${ }^{a}$ Foreign language department, Beijing institute of fashion technology, Beijin, China \\ bForeign language department, Beijing institute of fashion technology, Beijin, China
}

\begin{abstract}
The paper begins with the concept and ideas of multimedia teaching and computer-aided multimedia teaching, illustrates the principles of optimal integration between computer-aided multimedia teaching and traditional teaching, stresses how to balance the relationship between the learners and the teacher and how to benift from the teaching process, all these have just been shown with the figures and been developed by taking translation teaching as the sample, and the constructivist theory of scaffolding instruction has also been adopted as the theory basis, espeiclly to the the design, the Organization and the implement of the multimedia assisted translation teaching.
\end{abstract}

Index Terms: Computer-aided multimedia teaching; Translation teaching; Teaching process

(C) 2011 Published by MECS Publisher. Selection and/or peer review under responsibility of the International Conference on E-Business System and Education Technology

\section{Introduction}

As the multimedia and network techniques are developing rapidly and applied extensively in recent years, the computer-aided translation teaching mode which was focused by a few experts, is favored by a growing number of ordinary foreign language teachers and students now. The reform deepening of the multimedia assisted teaching made up the large gap in the traditional teaching mode, making the teaching method and process wonderful and brilliant. However, due to the diversities of different subjects in the teaching practices, the superiority in multimedia teaching differs in thousand ways, just as Warschauer said, using the Internet for foreign language teaching can be compared to taking a glass of water from a water injection of a fire hydrant[1]. This states that the foreign language teaching based on Internet has great potential, and implies the difficulty and complexity in the process[2][3]. The author intends to use English translation teaching as an example to explain the research and development of multimedia course system of translation teaching which based on network environment, and explore the mode of computer-aided translation teaching.

Corresponding author:

E-mail address: ${ }^{\mathrm{a}}$ zh-huiqin@163.com; ${ }^{\mathrm{b}}$ peng_00000123@163.com 


\section{Computer-aided multimedia teaching}

\subsection{Concepts and ideas of multimedia teaching and computer-aided multimedia teaching}

Multimedia teaching means that in teaching process, according to the teaching target and the teaching object, teachers should make scientific class designs, choose and apply modern teaching media reasonably, and combine it with the traditional teaching method, using a variety of media information to affect students, then form a perfect teaching process with an optimization teaching result.

Computer-aided multimedia teaching means using computer to achieve the combination of various multimedia, to deal with various multimedia information comprehensively, such as symbols, language, words, sound, graphics, images, etc., which possesses the characteristics of interactive, integration, controllable, etc. Then, according to the teaching requirements to shift the elements of multimedia to the organic combination, and displayed by the screen or projector projection, meanwhile, add the sound according to the need as well as manmachine interactive operation between user and computer to accomplish the teaching and training process

\subsection{The principle of optimal integration between computer-aided multimedia teaching and traditional teaching}

The final aim of optimal integration between computer-aided multimedia teaching and traditional teaching is to complete the learning task effectively, improve students' comprehensive quality and cognitive abilities. During the implementation process, the first principle which needed to be grasped is that teachers' are leading, while students' are subjective. Teacher is the dominant factor of teaching activities, student is the main part of learning activities, and also the object of teaching activities. Multi-media English teaching should make studentoriented, thinking development as the core, which based on abundant information resources, and supported by the modern information technology. Second, the principle of class interaction between the teacher and students: multimedia assisted computer English teaching should make the scientific teaching concept, teaching theory as the guidance, structure the interactive platform between teachers and students, realize the two-way communication between teachers and students, transform the teacher's role, from teacher-centered, teaching material-centered to student-centered, problem-centered, to inherit and carry forward the essence of traditional teaching theory in the dialectical way, rational use of traditional teaching ideas of "teach according to students aptitude", "inspire revulsive", "teaching benefits teachers as well as students", as well as "the unity of learning, knowing and acting", etc, pay attention to the teaching methods, emphasize on the abilities, with the help of modern multimedia network aided technology, through various means, such as online classroom to bring out the virtual context, the experience and feeling of students' can make themselves become the initiative constructor of knowledge gradually, attending the classroom teaching positively and effectively, truly achieve that teachingprogram is participated in making by student, content of courses is participated in selecting by student, modes of the teaching is participated in designing by students, classroom teaching is participated in assisting by students, key points of the problems is inquired by the assistance of students, answer ideas is explored actively by students, find errors can make students participate and analyze, the rights and wrongs can guide students to judge, while the comprehensive evaluation can invite students to complete "sunshine project". 


\section{Design of translation course based on multimedia technology}

\subsection{Organization and design of translation courses}

Computer-aided teaching translation, compared with the traditional translation teaching, by aid of modern teaching means to cultivate students' translation competence adequately, including language analysis and command, aesthetic judgment and presentation skills, two-way conversion and logic analytical skill; and help the students to break through the traditional teacher-student relationship in teaching conceptions, to realize some mutual-equality relationship between teachers and students, in which both sides have common view for implementing each teaching program with enthusiasm and initiative; meanwhile, in charge of the implementation of teaching plan, the choice of teaching method and teaching effect. The basic aim of multimedia aided translation teaching is to train students'competence of translation and strengthen students'cognition of the translation. Organizational process of contents of multimedia course translation is shown in fig 1.

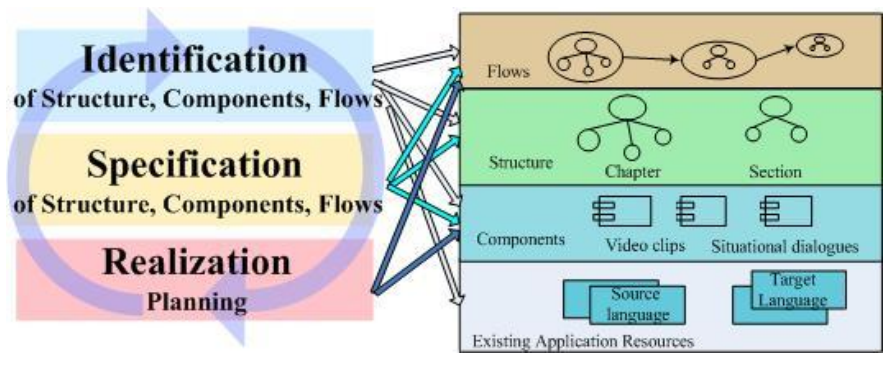

Fig 1. Organizational process of contents of multimedia translation course

The multimedia translation teaching should complete five tasks: first, stimulating thinking activities (grasp the significance to guide), which means to explore the inner meaning of original text in translation; second, the practical operation instruction (practice skills training), "operation" means the skills of bilateral switching and operation of translation, it is the embodiment of translation skills; third, theoretical research guide (theoretical studies), with the purpose of training students' cognitive competence, strengthen students' cognition of the translation and the nature of translation, especially for the cognition of quality, function and correlations in translation subject (translator), translation object (the original), recipient (reader, society), grasp translation method and approach, countermeasures and strategy, also the translation value standard of comparison system; forth, guiding students to understand the original text and arrange themselves, adjust the translation, pay close attention to the techniques of expression in translation, of the translation theory of performance, thinking principle of translating performance; fifth, guiding students to realize translation, pay close attention to ontological study of translation, and reflect translators" "self value" scientifically in the process of translation.

\subsection{Design of multimedia teaching system of translation course}

The aim of multimedia teaching system of translation course is to establish a teaching system that has a good interaction effects, it can realize the integrative auxiliary teaching system from base layer to interface layer, service layer and allocation layer in function, which including courseware demo, background material demo, teaching interaction management and courseware management, etc. The logical structure is shown in fig 2. 


\begin{tabular}{|c|c|c|c|c|c|c|c|c|}
\hline \multirow{2}{*}{ Apllication } & \multicolumn{8}{|c|}{ Multimedia Teaching \& Learning } \\
\hline & \multicolumn{8}{|c|}{ User Interfaces } \\
\hline Services & $\begin{array}{l}\text { Teaching } \\
\text { Material }\end{array}$ & \multicolumn{2}{|c|}{$\begin{array}{l}\text { Teaching } \\
\text { Design }\end{array}$} & \multicolumn{2}{|c|}{$\begin{array}{c}\text { Teaching } \\
\text { Methodology }\end{array}$} & ... & \multicolumn{2}{|c|}{$\begin{array}{c}\text { Teaching } \\
\text { Organisation }\end{array}$} \\
\hline \multirow{2}{*}{ Realization } & \multicolumn{8}{|c|}{ Procedure } \\
\hline & \multicolumn{3}{|c|}{ Databases } & & \multicolumn{4}{|c|}{ Procedure } \\
\hline \multirow[b]{2}{*}{ Basics } & \multirow{2}{*}{\multicolumn{2}{|c|}{$\begin{array}{l}\text { Computer } \\
\text { Networks }\end{array}$}} & \multicolumn{6}{|c|}{ Material } \\
\hline & & & $\begin{array}{l}\text { Image } \\
\text { Graph }\end{array}$ & & Animation & & adio & Video \\
\hline
\end{tabular}

Fig 2. Logical structure of multimedia teaching system of translation course

\subsection{Design of multimedia software system}

This system based on B/S structure, used ASP programming, and adopted Microsoft Access as database, the powerful functions and good database support of ASP can shorten the construction cycle of the software, and the system can proceed database connection through $\mathrm{ADO}$, multimedia files can produce by various tools (such as FlashMX, PowerPoint,Word, etc), the structure of software system is shown in fig 3 .

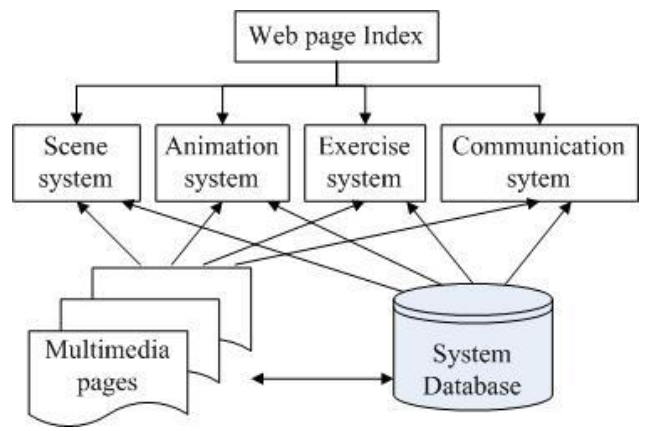

Fig 3. Structure of multimedia software system

\section{Organization and design of the contents of mmultimedia translation course}

The general idea of multimedia-aided translation teaching design is to conduct constructivism theory as the foundation, using multimedia technology, realizing the interaction between teachers and students to the most extent. In teaching practice, using sections and chapters as the basis unit, language function as the main line, practical translating tasks as the foundation, focusing on both vertical linkage and horizontal linkage of knowledge, to encourage students to expand and deepen when using knowledge. The whole class can be divided into three parts: first, introduction to the text; second, step into the text; third, sum up the lesson. Expand each part to inspire students' interests, to construct the environment which can benefit to the students' independent thinking, democratic debate, and then, to train the students' ability to think independently and their innovative 
spirit. Guided by the former design principles, the structure of the contents of multimedia translation course is shown in Fig 4.

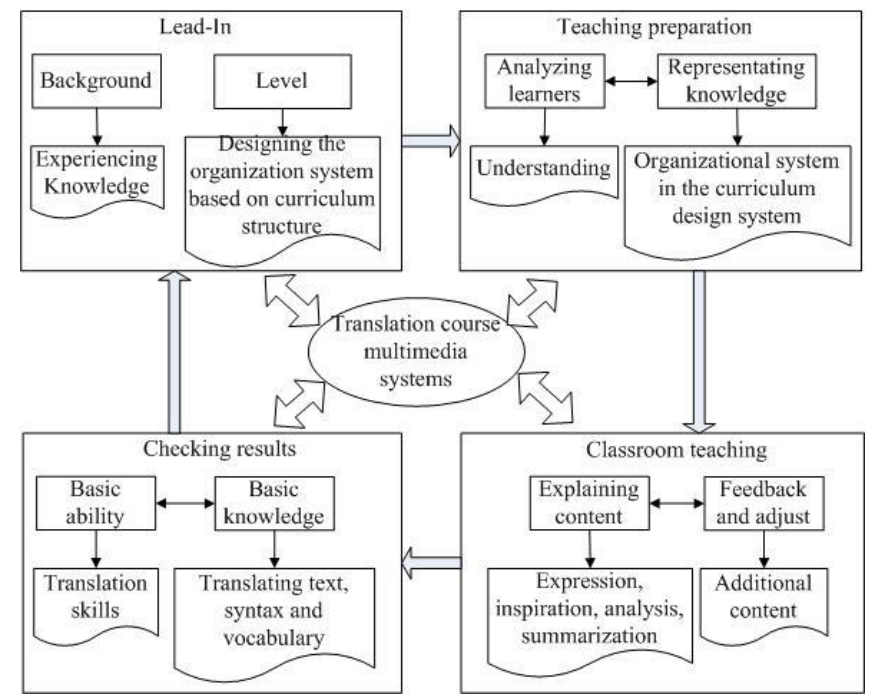

Fig 4. Structure of multimedia translation course

As learnt from Fig 4, the organization and design of the contents of multimedia translation courses should keep good balance of the following four relationships:

- The teacher's leading position and student's main body status. The teachers play leading roles in teaching course, an overall consideration of the courseware design, lecture rhythm, and each part always had a ready answer[4]. Meanwhile, in classroom, the teacher should be involved in controlling positively by observing, participating, touring, guiding, etc, adjusting each part according to the needs of the students, attaching the harmoniousness between the teacher's leading position and student's main body status. In order to help students to further the research of knowledge, advocate the academic habits of independent, selfimprovement and cooperative exploration.

- The associative relation of learning and thinking in multimedia teaching. The use of multimedia course enlarges the amount of information in class, but it must pay more attention to coordinate time difference between the speed of students' thinking and multimedia switching, grasp the time to let students stay to make notes, and ensure the overall coherence of classroom teaching, to avoid the stickup, writing, and the combination of sentence too fast, which given not enough time for the students to think and learn and finally appear the "spoon-feeding" teaching under the new technology condition.

- The coherent and collaborative relationship between classroom teaching and after-school tutoring. Considering the characteristics of richness and sharing in network resource, it should be connected among teaching content arrangement, decorate class arrangement, the preview, review, assignments, etc, the classroom teaching content and relevant supplementary information should be provided for students to browse through the campus network center, at the same time, opening teachers' public mailbox to communicate with students more conveniently. Enrich their translation activities in multiple channels, such as establishing translators association of school, holding relevant lectures; advocating English poem recitation contest, English speech competition, and establishing modern English to improve students' translation ability. 
- The proportional relationship between achievements in peacetime and terminal examination. For the examination of academic scores, it should take the combination between achievements in peacetime and terminal examination, establish personal file of student's learning, evaluate student's indivudaul partial performance in learning process from the teacher, the students evaluate each other according to the teacher's requirements in the random way, then take back after giving the signature. Learning and evaluation results of students' should be checked periodically, the final grade should be evaluated by achievements in peacetime and terminal examination, each part takes up 50\%. This approach can promote mutual understanding among the students, inspire autonomous learning enthusiasm, and help them to finish homework efficiently by discussing, communicating with each other.

\section{System implementation}

Comparing with traditional mode, we should coordinate the relationship between teachers and students in the progress of multimedia translation teaching through the computer-aided teaching methods(as shown in Fig5), and make best use of modern teaching methods to grasp every link and process of the teaching .

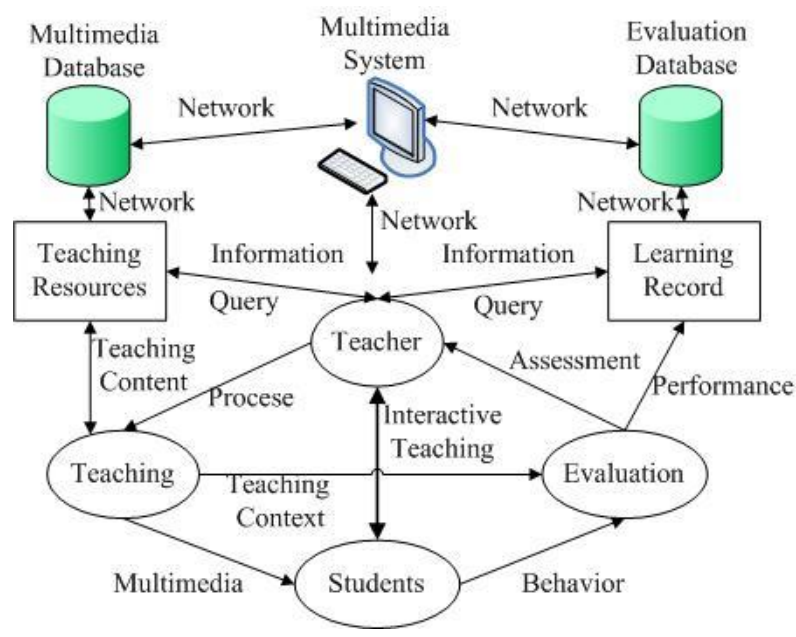

Fig 5. Implement organization relationship of multimedia translation teaching

- Help students enter the scene, encourage them to attempt collaborative learning on the basis of probing independently, and evaluated the effect. When making the introduction to the text, take advantages of multimedia technology to add relevant background knowledge into courseware, conduct practical operation of the students, and request them to make an overall assessment of the original in terms of the scene, then insert summary table of features of different literary translation under the dialogue, inspire the students to make group discussions, translate the original text from multiple angles according to the different understanding, realize the transformation between skills and techniques in translation step by step[5].

- Encourage students to probe independently. After finishing group discussion within the given time (about ten minutes), each group select the representatives to state concrete realization of the eight indexes in translating, such transposition thinking help to strengthen more understanding of the nature, function and correlations among translation subject (translator), translation object (original text), and recipient (readers, society), widen their sight, and form a standard of value in translation gradually. 
- Based on the good understanding of the original text, inspire students to make discourse as the unit to judge the original text according to the meaning, discuss in groups, and make a translation. According to the understanding of the group, the teacher should call the phases in electronic lesson plans which prepared before class, and take four different styles of versions as different examples for the students to read them through. In the interaction of translation practice, guide the students to control the translation process, and pay close attention on the performance of translation theory.

- Modify and complete the translation constantly by accepting students' advices, and make the whole analysis and adjust process displayed in the white board vividly according to the use of different color logo, then prompt students to notice the overall process of translation .

- After completing the translation, teacher inspires students to compare the translation text which cotranslated together to the reference version, rethink the original text from multiple angles to provide a better understanding of it, according to introducing the meaning of functionalism that "meaning is using" which suggested by Ludwig Wittgenstein in Philosophy Research, to guide students to understand translation, focusing on ontological study of translation, then promote the levels of translation theory.

- Based on the understanding of different translations, hiding the original text while showing the translation temporarily by using the advantages of multimedia, inspire and encourage students to make back-translation from translation to original text, focused aftertaste them, lead students to understand translation principles, conclude translation methods.

\section{Conclusion}

Multimedia technology has innovated the information transfer mode of translation theory and practice, set up a new teaching mode that the teacher acts as guide, while students act interactively, efficiency as the goal and intuitive way as the feature. We need to focus on the adoptation of multimedia for aiming at different functions of multimedia and the characteristics of the students, pay equal attention to translation theory and practice in the class design, Chinese-English translation theory and practice in equal, various kinds of examples in equal, and fully considering of the rhythm of teaching and students' feedback in course using. In this way it can bring out the general advantages of visibility, readability and interactivity, to make our translation theory and practice class to life and interesting.

\section{REFERENCES}

[1] Warcshauer,M. CALLvs.electronic literacy: reconceiving technology in the language classroom. Retrieved on Decemnber 2, 2003, pp. 270-276.

[2] Mai Neo and Ken T. K. Neo. Innovative teaching: Using multimedia in a problem-based learning environment. Educational Technology \& Society 4(4) 2001, pp. 19-31.

[3] Haris Supic, Member, IAENG. An Adaptive Multimedia System for Teaching Fundamentals of Finite Element Method Using the Case-based Content Sequencing. Proceedings of the World Congress on Engineering 2009 Vol I, pp. 121-129.

[4] Zhang huiqin. On Silence in College English Classrooms. Foreign Languages in China. 2009,6, pp. 80-86.

[5] Zhang huiqin. A Study on the Application of Multi-media Technology in Translation Teaching. Foreign Languages and Their Teaching. 2007,12, pp.38-42. 